\title{
Synthesis of Some Heterocyclic Compounds Derived From 2-Amino Benzothiazole
}

\author{
Zainab M. Mahmood ${ }^{1 *}$, Ahmad Kh. Ahmad ${ }^{2}$ \\ ${ }^{1,2}$ Department of Chemistry, College of Education for Pure Sciences, University of Mosul, Mosul, Iraq \\ E-mail: ${ }^{1 * a l b d r a n y z y n a b @ g m a i l . c o m, ~}{ }^{2}$ ahmad_alkhayat@unmosul.edu.iq
}

(Received July 06, 2020; Accepted August 11, 2020; Available online December 01, 2020)

DOI: 10.33899/edusj.2020.127562.1087, (c) 2020, College of Education for Pure Science, University of Mosul.

This is an open access article under the CC BY 4.0 license (http://creativecommons.org/licenses/by/4.0/).

\begin{abstract}
In this paper, number of heterocyclic compound with five and six membered, Such as substituted imidazole, triazin and thiazolidine. The compound $\mathrm{N}-(1,3$-benzothiazol-2-yl)-2-chloro acetamide was prepared from the reaction of the 2-amino benzothiazole with chloroacetyl chloride. The product $\mathrm{N}$ (1,3-benzothiazol -2-yl) -2-chloro acetamide was reacted with thiourea and urea to prepare both 4 (1.3-benzothiazol -2-yl amino) -1,5-dihydro - $2 \mathrm{H}$-imidazole -2-thione and 4-(1,3-benzothiazol -2-yl amino) -1,5-dihydro -2H-imidazol -2-one, respectively. As did compound N-(1,3-benzothiazol -2-yl) -2-chloro acetamide with thiosemicarbazide and semicarbazide to prepared the two compounds 5(1,3-benzothiazol -2-yl amino) -1,6-dihydro -1,2,4-triazine -3(2H)-thione and 5-(1,3-benzothiazol -2yl amino) -1,6-dihydro -1,2,4-triazine -3(2H)-one, respectively. Also compound N-(1,3-benzothiazol -2-yl) -2-chloro acetamide with ammonium thiocyanate to prepare the compound 3-(1,3-benzothiazol -2-yl amino) thiazolidin -4-one. From the reaction of compound N-(1,3-benzothiazol -2-yl) -2-chloro acetamide with phenyl thiourea attended 4-(1,3-benzothiazol -2-yl amino) -1-phenyl -1,5 -dihydro $2 \mathrm{H}$-imidazole -2-thio. Also from the reaction of 2-amino benzothiazole with phthalic anhydride or malic anhydride attended compounds2- (1,3-benzothiazol -2-yl carbonyl) benzoic acid and 4-(1,3benzothiazol -2-yl amino) -4-oxobut-2-enoic acid
\end{abstract}

and 2-(1H-benzoimidazol -2-yl) -N-(1,3-benzothiazol -2-yl) benzamide and 3-(1H-benzoimidazol -2yl) -N-(1,3-benzothiazol -2-yl) acrylamide, respectively. And by reaction compound 2- (1,3benzothiazol -2-yl carbonyl) benzoic acid and 4-(1,3-benzothiazol -2-yl amino) -4-oxobut-2-enoic acid or 2-(1H-benzoimidazol -2-yl) -N-(1,3-benzothiazol -2-yl) benzamide and 3-(1H-benzoimidazol -2yl) -N-(1,3-benzothiazol -2-yl) acrylamide with o-phenylene diamine attended compounds $2-(1 \mathrm{H}-$ benzoimidazol -2-yl) -N-(1,3-benzothiazol -2-yl) benzamide and 3-(1H-benzoimidazol -2-yl) $-\mathrm{N}$ (1,3-benzothiazol -2-yl) acrylamide, respectively. The synthesized compounds are identified by physical melting points, color change and spectroscopic methods such as IR, proton-NMR.

Keywords: 2-amino benzothiazole ; thiazolidine ; imidazole

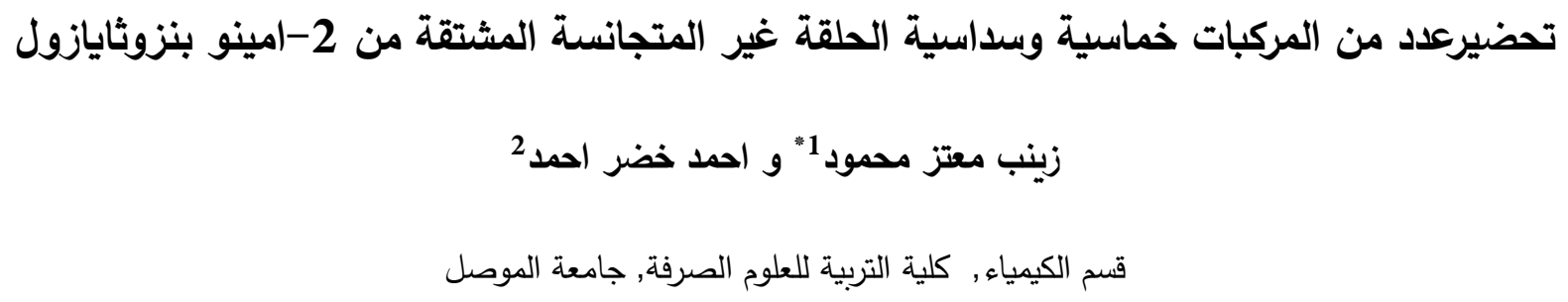


تم في هذا البحث تحضير عدد من المركبات الحلقية غير المتجانسة خماسية وسداسية الحلقة مثل الايميدازول والترايازين

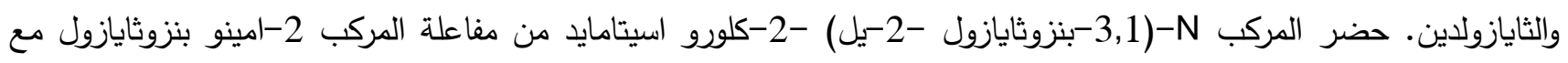
كلورو اسيتايل كلوريد, فوعل المركب N-N

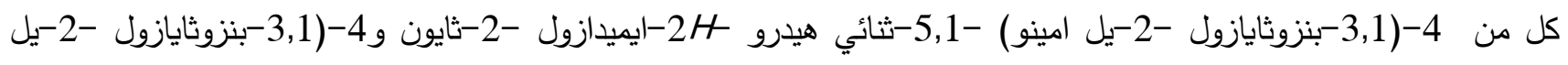

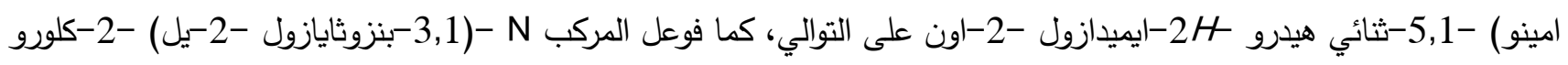

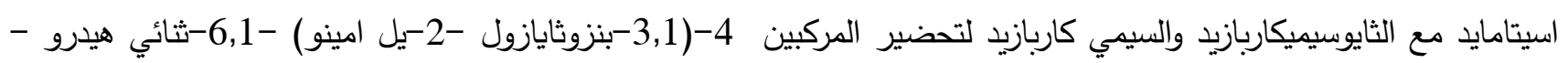

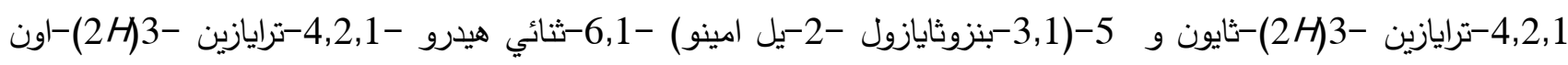

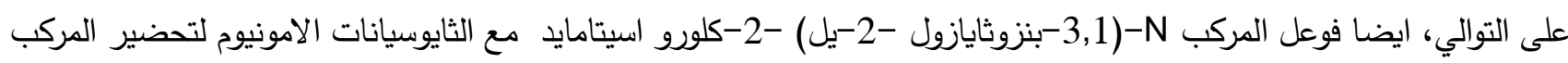

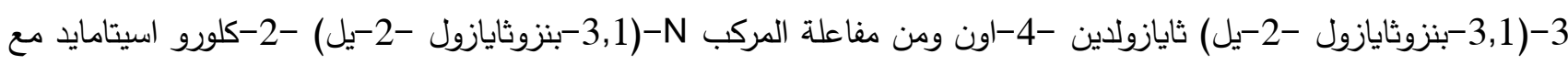

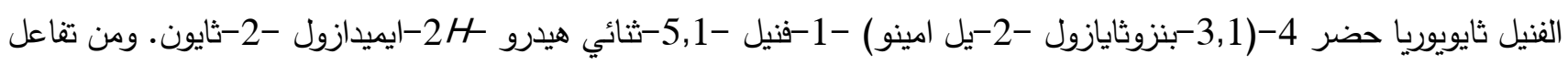

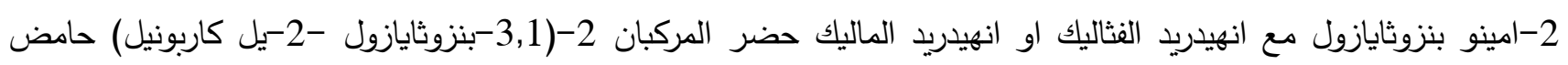

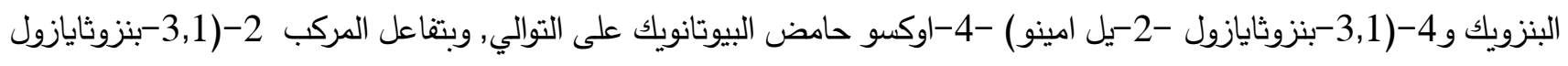
-2-2يل كاربونيل) حامض البنزويك و 4-3,1-بنزوثايازول -2-1) -

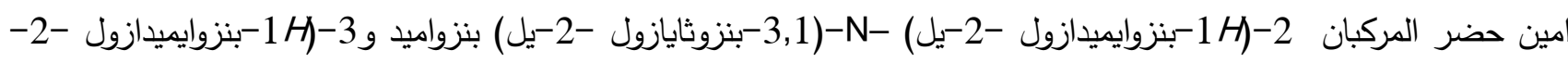

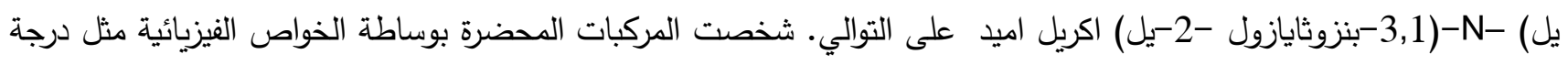
الانصهار , تغير اللون وكذلك الطرائق الطيفية مثل الاشعة تحت الحمراء , الرنين النووي المغناطيسي للبروتون.

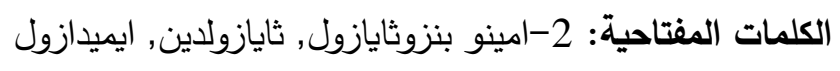

المقدمة

ان البنزوثايازول احد المركبات العضوية غير المتجانسة المهمة التي لها طيف واسع من النشاط البيولوجي حيث تلعب دورا مهما في المجال الطبي. كذلك فأن حلقات البنزوثايازول المعوضة لها اهية كبيرة في الصيغة الكيميائية للأدوية المستخدمة في علاج

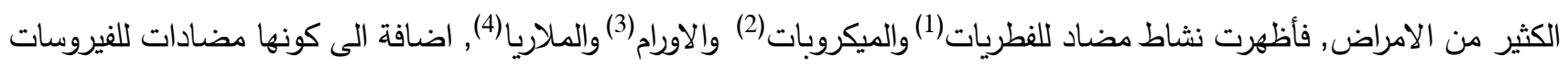

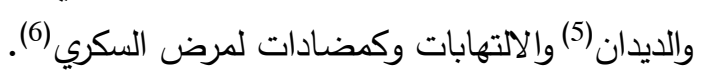
استخدم المركب 2-امينو بنزوثايازول لتحضير مركبات حلقية خماسية وسداسية غير متجانسة ومنها الايميدازول والثايازولدين والترايازين. التي اظهرت الدراسات لهذه المشتقات اهمية كبيرة بسبب استخداماتها الواسعة في المجال الصناعي والزراعي والطبي. ان ما يميز هذه المركبات عن بعضها البعض هو نوع التعويض على الحلقية غير المتجانسة الذي يؤثر على نحو كبير في الفعالية البيولوجية لهذه المركبات.

تعد الايميدازولات مركبات اروماتية خماسية الحلقية غير المتجانسة تحتوي على ذرتي نتروجين غير متجاورتين. ان مشتقات

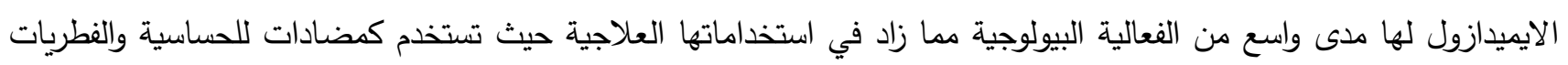

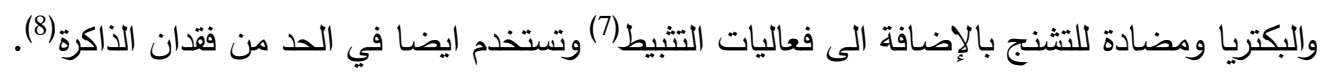

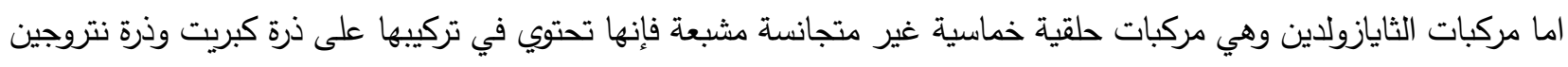
في الموقعين (1,3) على التوالي. ان حلقة الثايازولدين المكون الاساسي لعدد كبير من المستحضرات الصيدلانية التي لها فعالية

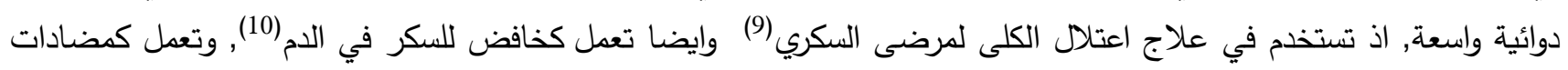


للميكروبات(11) والفيروسات والاورام ولفيروس نقص المناعة البشرية(12) ومضادا للفطريات (13) كما تعمل مضادات للالتهابات ومسكنة

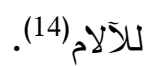

والترايازين مركبات أروماتية سداسية الحلقة غير المتجانسة تحتوي على ثلاث ذرات نتروجين. وللترايازين طيف واسع من الانشطة الدوائية فبعضها تعمل كمضادات للفطريات والفيروسات والالتهابات كما تعمل كمضادات لفيروس نقص المناعة المكتسبة وبعضئها يستخدم لعلاج السرطان والسل ومنشط للذهن (15)(16)(17). وتهدف الدراسة الى تحضير عدد من المركبات الحلقية غير المتجانسة (الايميدازول, الثايازولدين, الترايازين). الجزء العملي

الاجهزة والمواد الكيمياوية المستخدمة: - جميع المواد الكيمياوية المستخدمة من انتاج الشركات (BDH) و (FLUKA) (FLA). وتستخدم بدون تتقية. : (M.P.) (جهاز قياس درجة الانصهار Electrothermal melting point Apparatus 9300 (not corrected). -جهاز طيف الاشعة تحت الحمراء : Bruker Alpha FTIR, Germany, Tensor-27 and Fourier Transform Infrared spectrophotometer model shimadzu-FTIR-8400S.

- جهاز طيف الرنين النووي المغناطيسي للبروتون (1H-NMR): تم القياس لبعض من المركبات المحضرة في جامعة عثمان باشا توكات / تركيا واستخدم TMS كمرجع باستخدام Hz -Bruker Biospin Gmb H (400 MHz)

1 - تحضير - 1 $\mathrm{N}$-(1,3-benzothiazol -2-yl) -2-chloro acetamide يذاب (0.005mole,0.75gm) 2) 20.امينو بنزوثايازول في (30ml) حامض الخليك التلجي ثم يضاف على شكل قطرات مع التحريك (0.032mole,3.9gm) كلورو استيايل الكلوريد. يصعد مزيج التفاعل لمدة (5) ساعات. يصب الناتج على ثلج

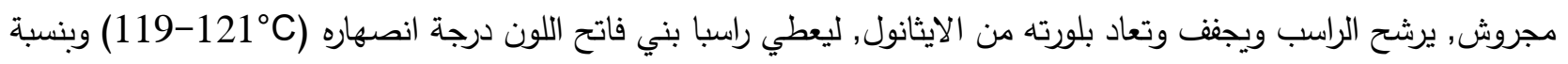
ناتج (64\%).

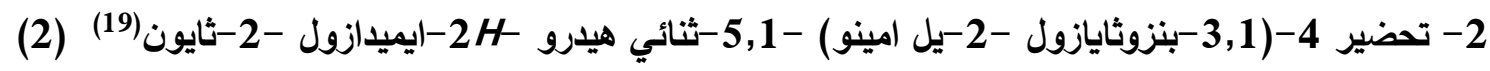
4-(1.3-benzothiazol -2-yl amino) -1,5-dihydro -2H-imidazole -2-thione يصعد مزيج (0.001 mole,0.2gm) من المركب (1) مع (15mle,0.076gm) ثايويوريا في (15) من ثنائي مثيل فورماميد جاف مع (0.001mole,0.1gm) من كاربونات البوتاسيوم اللامائية. لكدة (9-8) ساعات. يبرد الناتج الى درجة حرارة الغرفة ويضاف اليه الماء المثلج, يرشح الراسب ويجفف وتعاد بلورته من الايثانول. ليعطي راسبا اصفر درجة انصهاره (-183 (40\%) وبنسبة ناتج (185\% C

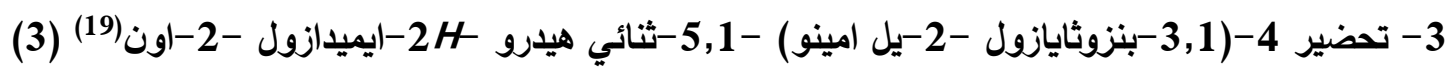
4-(1,3-benzothiazol -2-yl amino) -1,5-dihydro - 2H-imidazol -2-one 
حضر بنفس الطريقة (2) باستخدام (329de,0.015gm) اليوريا بدل الثايويوريا. ليعطي راسبا بني فاتح درجة انصهاره (329dec)

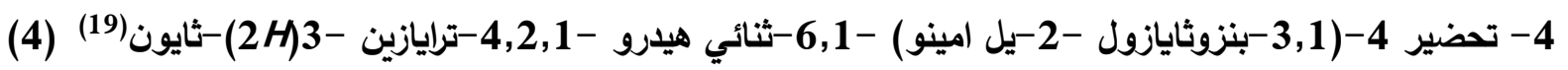
5-(1,3-benzothiazol -2-yl amino) -1,6-dihydro -1,2,4-triazine -3(2H)-thione حضر بنفس الطريقة (2) باستخدام (0.001 mole,0.09gm) الثايوسيمي كاربازيد بدل الثايويوريا. ليعطي راسبا بني فاتح درجة

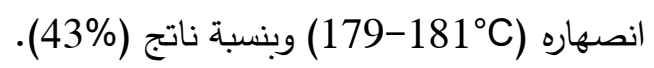

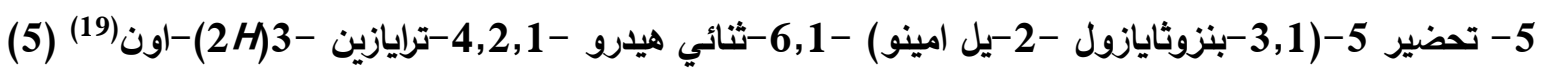
5-(1,3-benzothiazol -2-yl amino) -1,6-dihydro -1,2,4-triazine -3(2H)-one حضر بنفس الطريقة (2) باستخدام (0.001mole,0.075gm) السيمي كاربازيد بدل الثايويوريا. ليعطي راسبا بني فاتح درجة انصهاره (179º C

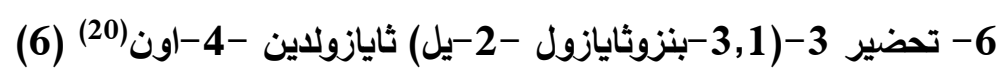
3-(1,3-benzothiazol -2-yl amino) thiazolidin -4-one يصعد مزيج (0.001mole,0.2gm) من المركب (1) و) ثايوسيانات الامونيوم في (30ml) ايثانول المطلق لمدة ساعة في حمام مائي. يترك المحلول الناتج لمدة (24) ساعة ثم يرشح الراسب ويجف ونت ونعاد بلورته من الايثانول. ليعطي راسبا بني اللون درجة انصهاره (203º

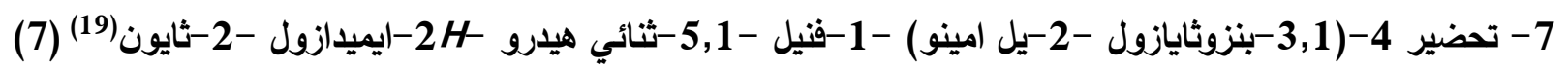
4-(1,3-benzothiazol -2-yl amino) -1-phenyl - 1,5 -dihydro - $2 \mathrm{H}$-imidazole -2-thione حضر كما في الطريقة (2) باستخدام (0.001mole,0.15gm) الفنيل ثايويوريا بدل الثايويوريا. ليعطي راسبا بني مصفر

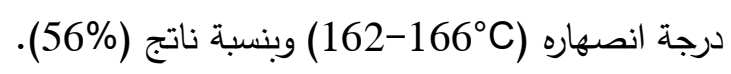

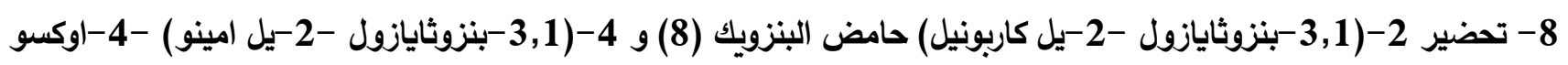
حامض البيوتانويك (9) (21) 2- (1,3-benzothiazol -2-yl carbonyl) benzoic acid and 4-(1,3-benzothiazol -2-yl amino) 4-oxobut-2-enoic acid يمزج (0.005mole,0.75gm) من 2-امينو بنزوثايازول و(0.005mole) من انهيدريد الفثاليك او انهيدريد الماليك اللامائي في (25ml) حامض الخليك التلجي. يصعد مزيج التفاعل لمدة (3) ساعات ثم يبرد الناتج ويرشح الراسب وتعاد بلورته من الدايوكسان.

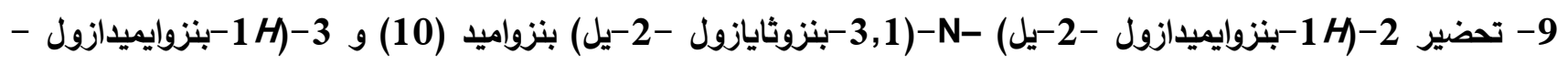
(22) اكريل اميد (11)-2,1)-N- (بنزوثايازول 2-(1H-benzoimidazol -2-yl) -N-(1,3-benzothiazol -2-yl) benzamide and 3-(1Hbenzoimidazol $-2-\mathrm{yl})-\mathrm{N}-(1,3-$ benzothiazol $-2-\mathrm{yl})$ acrylamide يصعد (0.005mole) من المركب (10) او(11) و) من اورثو فنيلين ثنائي امين في (10.005mole) من الايثانول

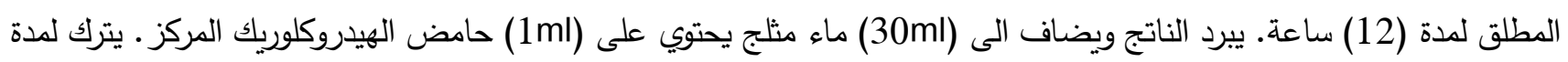
ساعة في درجة حرارة الغرفة. يرشح الراسب ويجفف وتعاد بلورته من الايثانول. لئرد 
الجدول (1): الخواص الفيزيائية للمركبات المحضرة

\begin{tabular}{|c|c|c|c|c|}
\hline $\begin{array}{c}\text { comp. } \\
\text { No. }\end{array}$ & $\begin{array}{c}\text { Molecular } \\
\text { formula }\end{array}$ & m.p. $\left({ }^{\circ} \mathrm{C}\right)$ & $\begin{array}{r}\text { Yield } \\
(\%)\end{array}$ & Color \\
\hline 1 & $\mathrm{C}_{9} \mathrm{H}_{7} \mathrm{CIN}_{2} \mathrm{OS}$ & $119-121$ & 64 & بني فاتح \\
\hline 2 & $\mathrm{C}_{10} \mathrm{H}_{8} \mathrm{~N}_{4} \mathrm{~S}_{2}$ & $183-185$ & 40 & اصغر \\
\hline 3 & $\mathrm{C}_{10} \mathrm{H}_{8} \mathrm{~N}_{4} \mathrm{OS}$ & $329 d$ & 30 & بني فاتح \\
\hline 4 & $\mathrm{C}_{10} \mathrm{H}_{9} \mathrm{~N}_{5} \mathrm{~S}_{2}$ & $179-181$ & 43 & اصفر \\
\hline 5 & $\mathrm{C}_{10} \mathrm{H}_{9} \mathrm{~N}_{5} \mathrm{OS}$ & $177-179$ & 52 & بني \\
\hline 6 & $\mathrm{C}_{10} \mathrm{H}_{8} \mathrm{~N}_{2} \mathrm{OS}_{2}$ & 200-203 & 59 & بني فاتح \\
\hline 7 & $\mathrm{C}_{16} \mathrm{H}_{12} \mathrm{~N}_{4} \mathrm{~S}_{2}$ & $162-166$ & 56 & بني-مصفر \\
\hline 8 & $\mathrm{C}_{15} \mathrm{H}_{10} \mathrm{~N}_{2} \mathrm{O}_{3} \mathrm{~S}_{2}$ & $240-243$ & 51 & ابيض \\
\hline 9 & $\mathrm{C}_{11} \mathrm{H}_{8} \mathrm{~N}_{2} \mathrm{O}_{3} \mathrm{~S}$ & $75-77$ & 41 & بني فاتح \\
\hline 10 & $\mathrm{C}_{21} \mathrm{H}_{14} \mathrm{~N}_{4} \mathrm{OS}$ & $262-264$ & 45 & بني غامق \\
\hline 11 & $\mathrm{C}_{17} \mathrm{H}_{12} \mathrm{~N}_{4} \mathrm{OS}$ & $195-197$ & 40 & بني غامق \\
\hline
\end{tabular}

النتائج وإلمناقثة

في هذا البحث تم استخدام 2-امينو بنزوثايزول كنواة لتحضير عدد من المركبات خماسية وسداسية الحلقة غير المتجانسة حسب المخطط التالي:

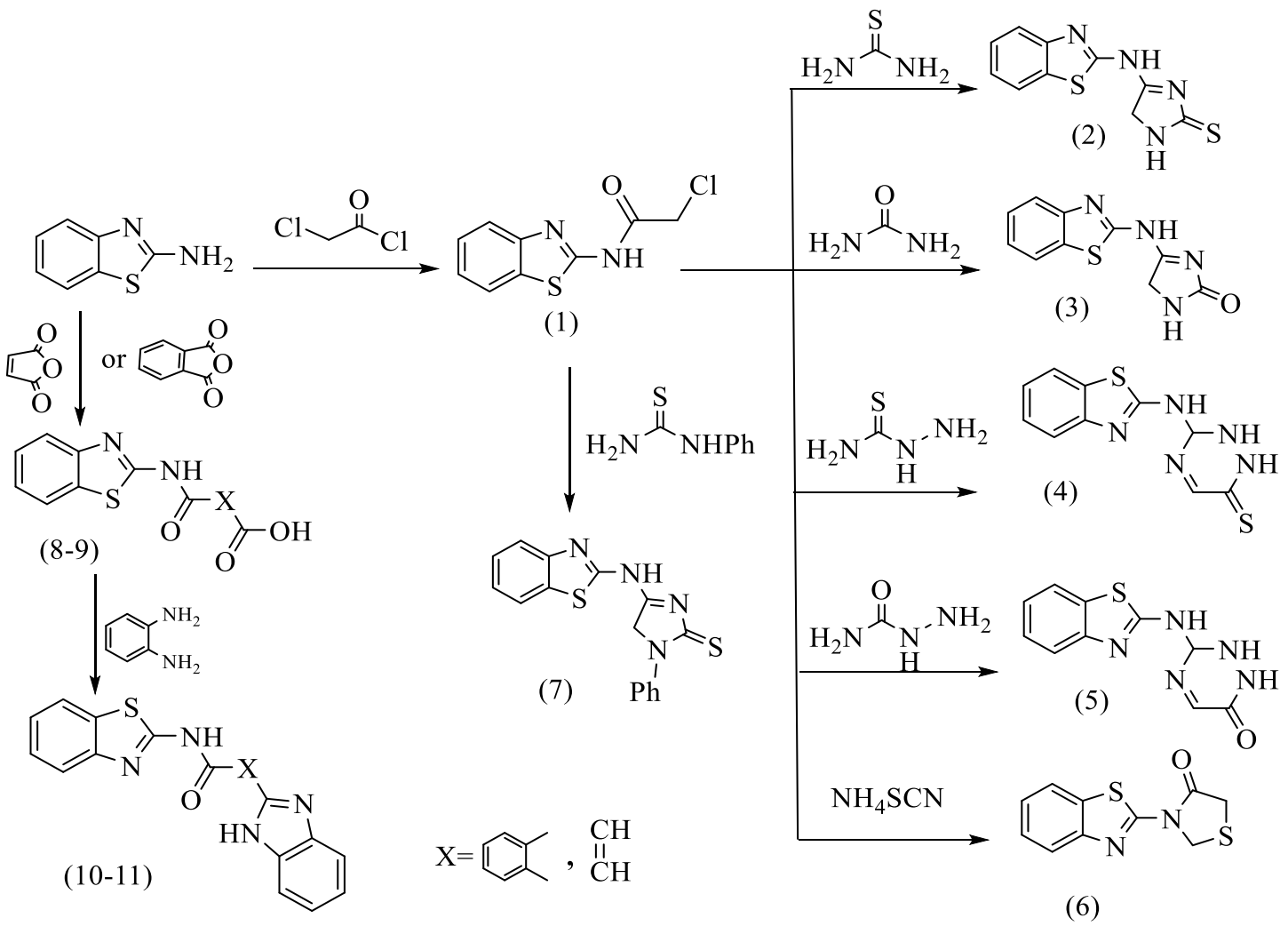
المخطط (1): يوضح المخطط العام لتحضير مشتقات الابميدازول والترايازين والثايازولدين 
حضر المركب N-N,1-بنزوثازول -2-2-2) -2-كلورو استامايد(1) من مفاعلة 2-امينو بنزوثايازول مع كلورو اسيتايل كلوريد في حامض الخليك التلجي, شخص هذا المركب المحضر طيفيا باستخدام الاشعة تحت الحمراء , اذ اعطى الطيف حزمة عند

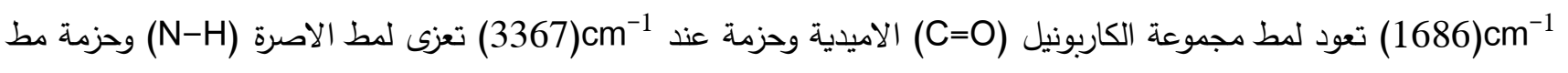

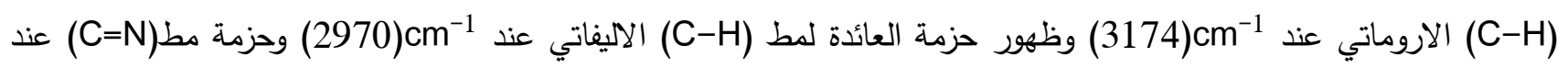

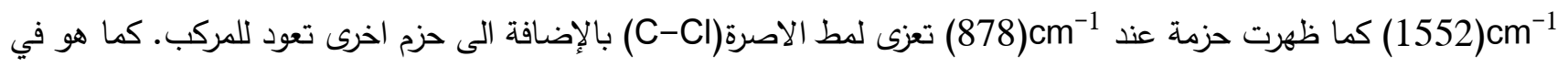
الجدول (2).

حضر الايميدازول -2-ثايون(2) والايميدازول -2-اون(3) من تفاعل المركب(1) مع الثايويوريا او اليوريا على التوالي بوجود كاربونات البوتاسيوم اللامائية في ثنائي مثيل فورماميد الجافئ.

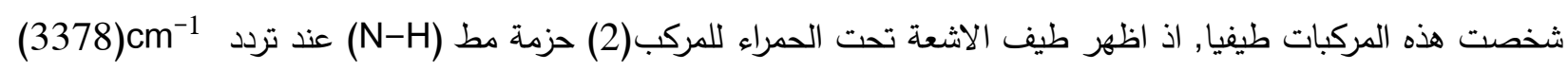

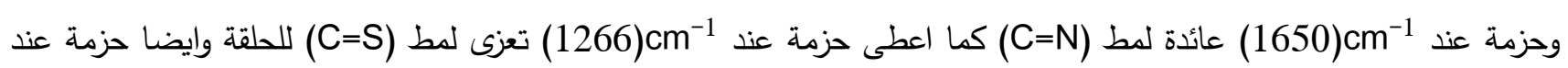
(1365)cm²

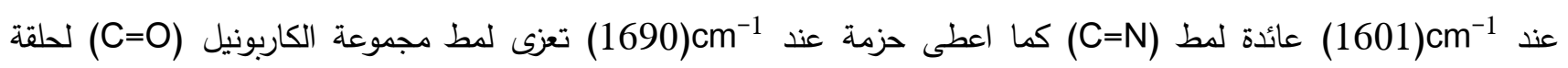

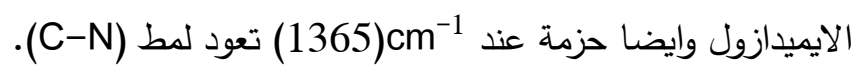

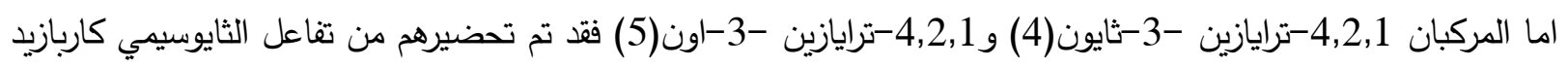

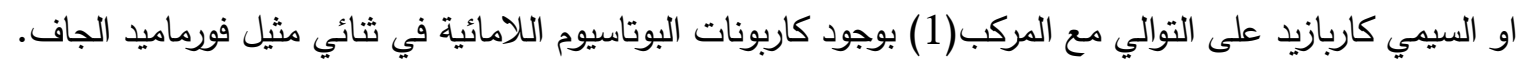

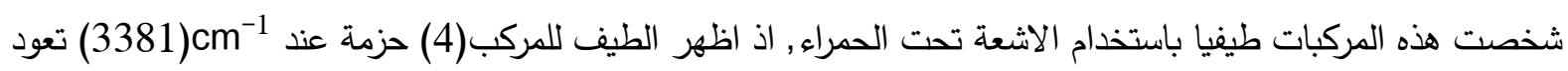

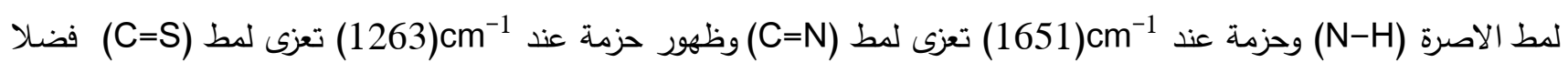

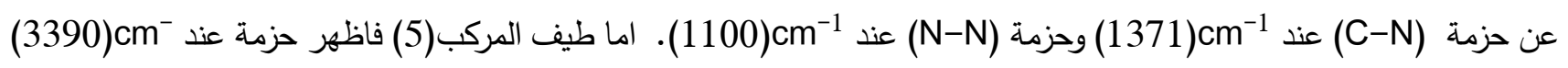

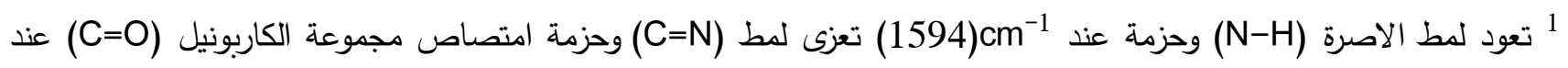
(1665)cm cm $^{-1}$

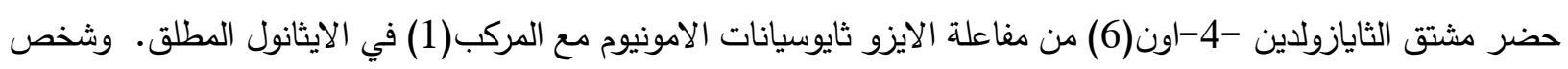
هذا المركب طيفيا اذ اظهر طيف الاثعة تحت الحمراء حزمة عند

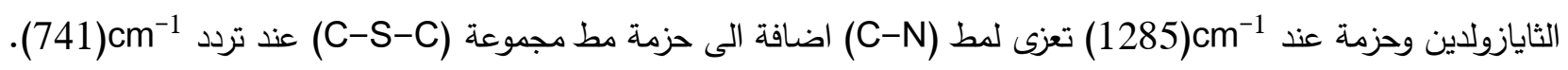

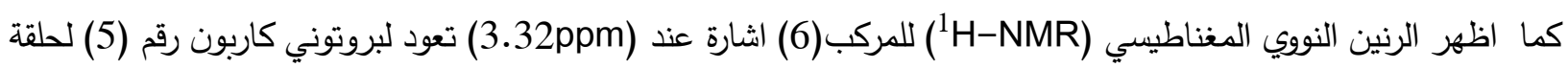
الثايازولدين وظهور اشارة اخرى عند الموقع (4.05ppm) تعزى لبروتوني الكاربون رقم (2) لحلقة الثايازول. كما اظهر اشارة متداخلة

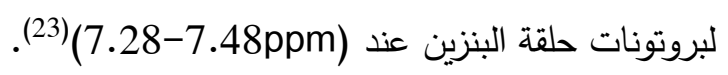
اما مركب الايميدازول -2-ثايون(7) حضر من تفاعل المركب(1) مع الفنيل ثايويوريا بوجود كاربونات البوتاسيوم اللامائية في

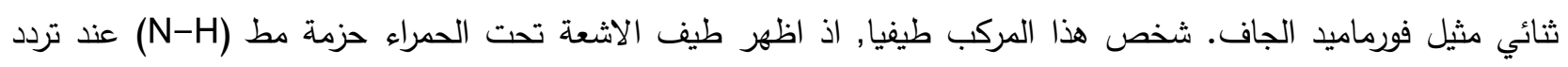

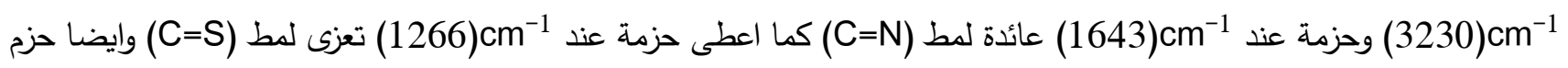

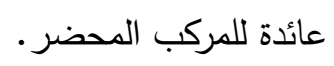
كما حضر المركبان (8) و(9) من مفاعلة 2-امينو بنزوثايازول مع انهيدريد الفثاليك او انهيدريد الماليك في حامض الخليك

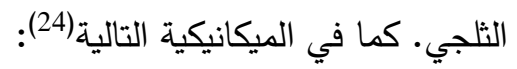




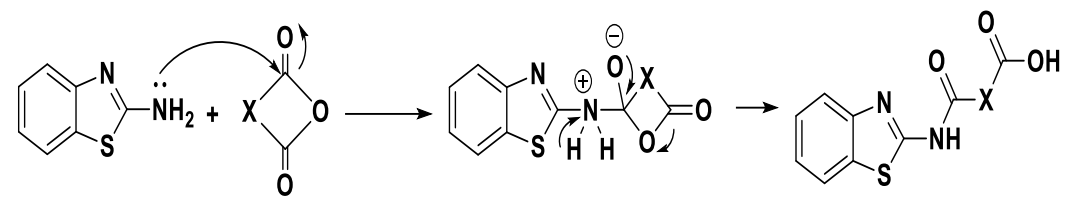

$$
x=\underset{N}{\stackrel{C H}{C H}}
$$

$(8-9)$

$$
\text { المخطط (2): يوضح تحضير المركبين (8) و(9). }
$$

شخصت هذه المركبات بوساطة طيف الاشعة تحت الحمراء, اذ اظهر الطيف للمركب(8) حزمة عند التردد تعود لمط (N-H) كما اظهر حزمة عند (3596) عائدة لمط (O-H) كما اعطى حزمة عند تردد

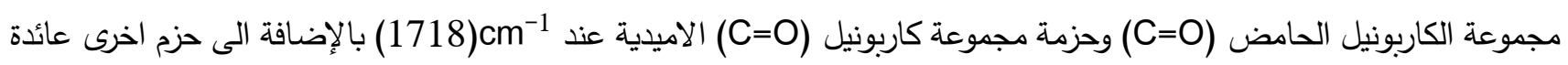
للمركب المحضر • اما طيف المركب(9) فاعطى حزمة عند تردد تردد تردد للمركبان المحضرة. وبمفاعلة المركبين (8) او(9) مع الاوثو فنيلين ثنائي امين في الايثانول المطلق لتحضير المركبين (10) و(11),على التوالي.

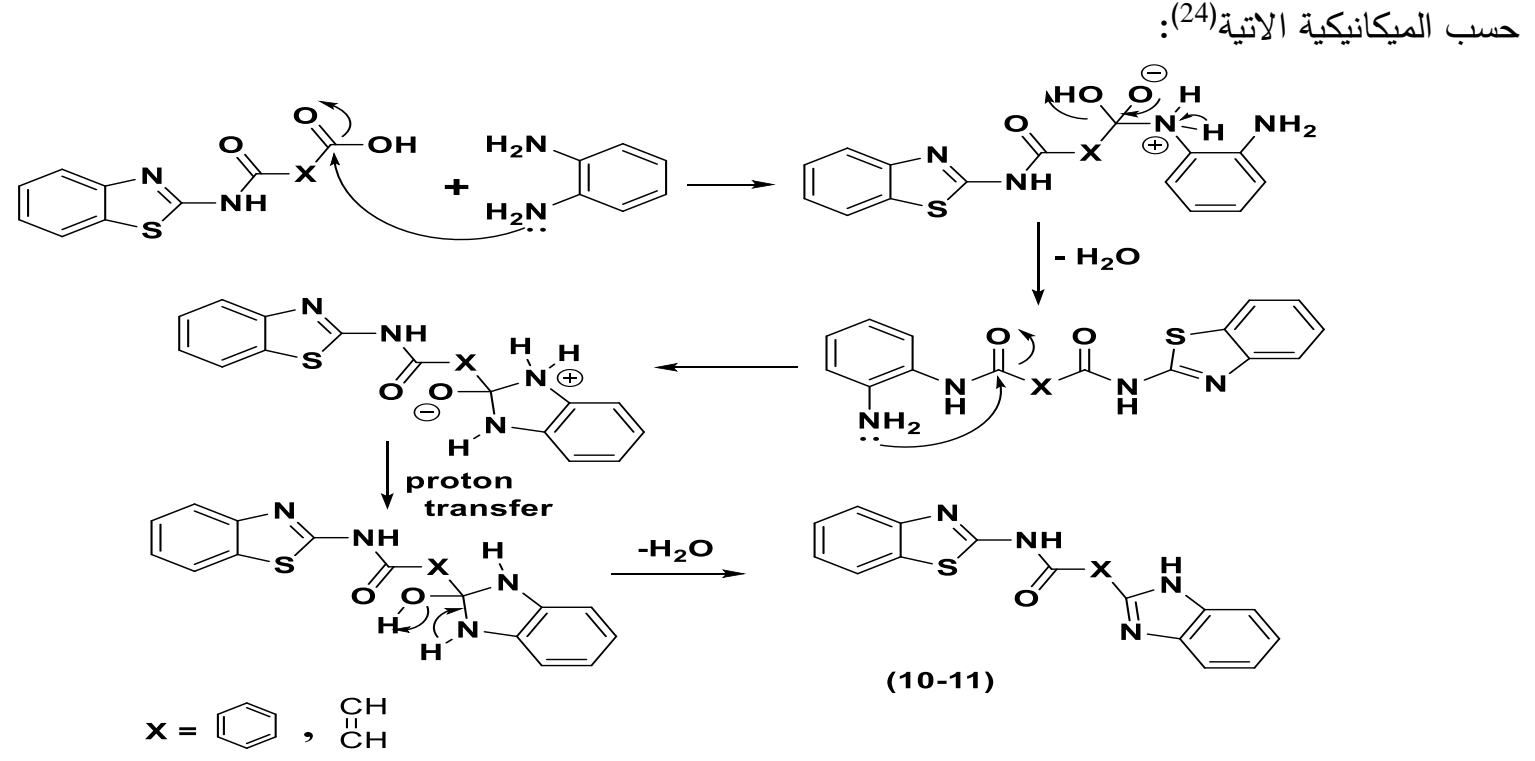

المخطط 3: يوضح ميكانيكية تحضير المركبات (10) و(11).

شخصت هذه المركبات طيفيا بوساطة طيف الاشعة تحت الحمراء, اذ تميز الطيف باختفاء حزمة (O-H) وحزمة مجموعة كاربونيل الحامض (C=O) ايضا, حيث اظهر طيف المركب(10) حزمة مط مجموعة (N-H) عند تردد

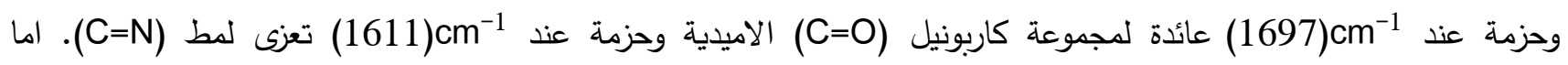

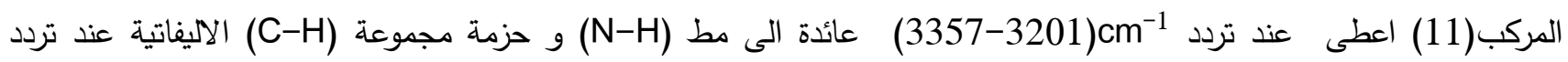

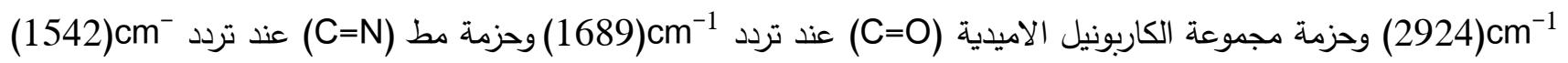
1. بالإضافة الى حزم اخرى عائدة للمركبان المحضرة. 
كما اظهر طيف الرنين النووي المغناطيسي (6.63ppm) تعود لبروتون

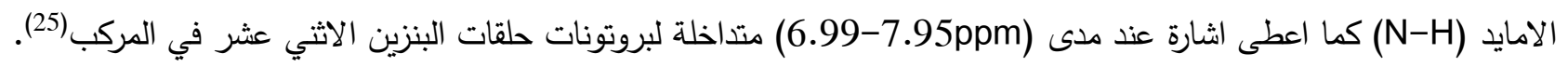

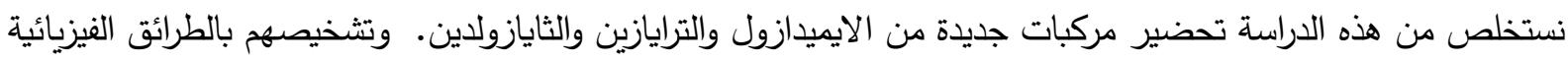
والطيفية .

الجدول (2): يوضح طيف الاثعة تحت الحمراء للمركبات المحضرة

\begin{tabular}{|c|c|c|c|c|c|c|c|c|}
\hline \multirow{2}{*}{$\begin{array}{c}\text { Comp. } \\
\text { No. }\end{array}$} & \multicolumn{7}{|c|}{$\mathrm{IR} v \mathrm{~cm}^{-1}$} & \multirow{2}{*}{ Other } \\
\hline & $\mathrm{O}-\mathrm{H}$ & $\mathrm{N}-\mathrm{H}$ & $\mathrm{C}=\mathrm{O}$ & $\mathrm{C}=\mathrm{N}$ & $\mathrm{N}-\mathrm{N}$ & $C=S$ & $\mathrm{C}-\mathrm{N}$ & \\
\hline 1 & - & 3367 & 1686 & 1552 & - & - & 1225 & $878(\mathrm{C}-\mathrm{Cl})$ \\
\hline 2 & - & 3378 & - & 1650 & - & 1266 & 1365 & - \\
\hline 3 & - & 3381 & 1690 & 1601 & - & - & 1362 & - \\
\hline 4 & - & 3381 & - & 1651 & 1100 & 1263 & 1371 & - \\
\hline 5 & - & 3390 & 1665 & 1594 & 1269 & - & 1367 & - \\
\hline 6 & _- & _ & 1694 & 1554 & - & _- & 1285 & $741(\mathrm{C}-\mathrm{S}-\mathrm{C})$ \\
\hline 7 & _ & 3430 & _- & 1643 & _ & 1262 & 1361 & - \\
\hline 8 & 3596 & 3358 & 1718 & 1553 & _ & - & 1280 & $1782(\mathrm{C}=\mathrm{O}$ acid $)$ \\
\hline 9 & 3512 & 3201 & 1699 & 1548 & - & - & 1271 & $\begin{array}{l}\text { 1682(C=O acid) } \\
2982 \text { (C-H Alp.) }\end{array}$ \\
\hline 10 & - & $\begin{array}{l}3458 \\
3357\end{array}$ & 1697 & 1611 & - & - & 1274 & - \\
\hline 11 & - & $\begin{array}{l}3357 \\
3201\end{array}$ & 1689 & 1542 & - & - & 1266 & 2924(C-H Alp.) \\
\hline
\end{tabular}

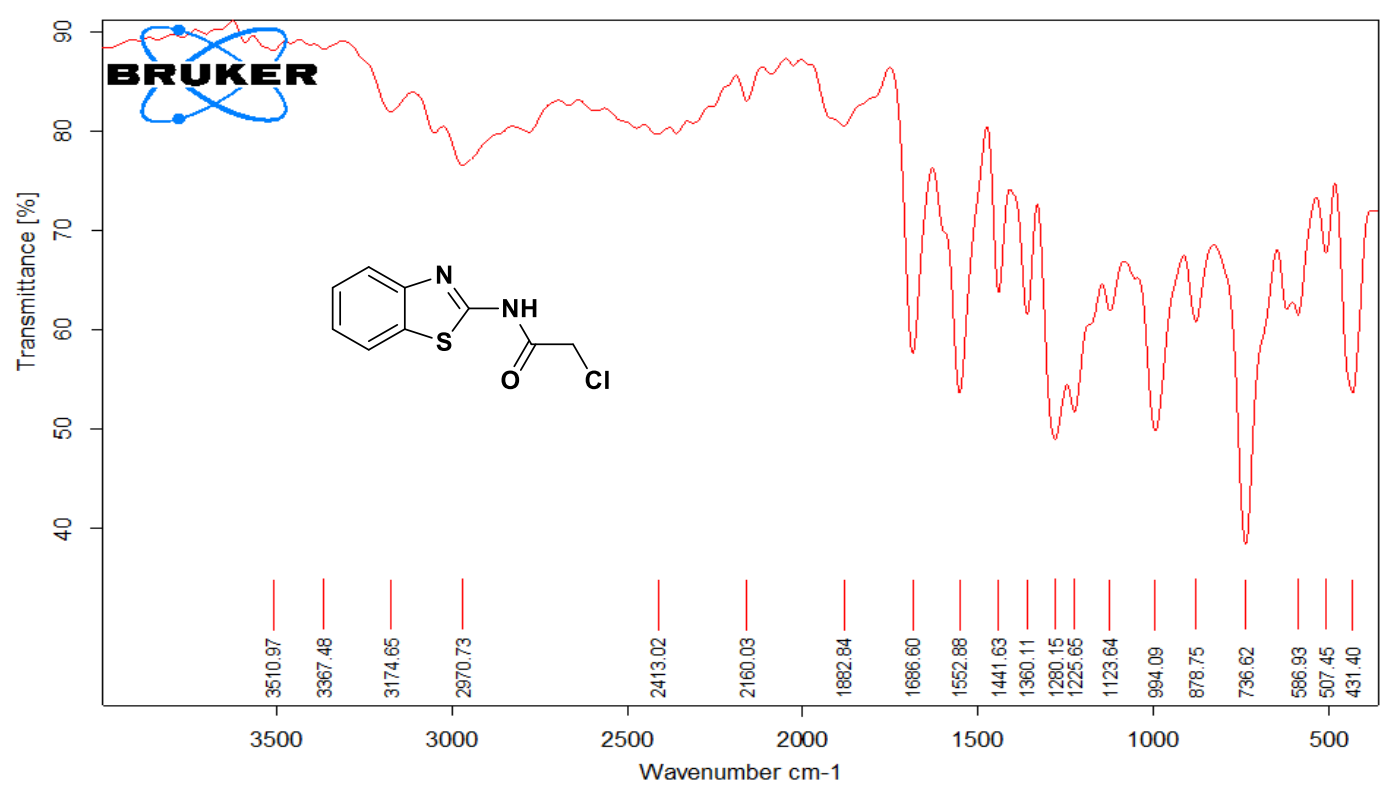

الثكل (1): يوضح طيف الاشعة تحت الحمراء للمركب (1) 


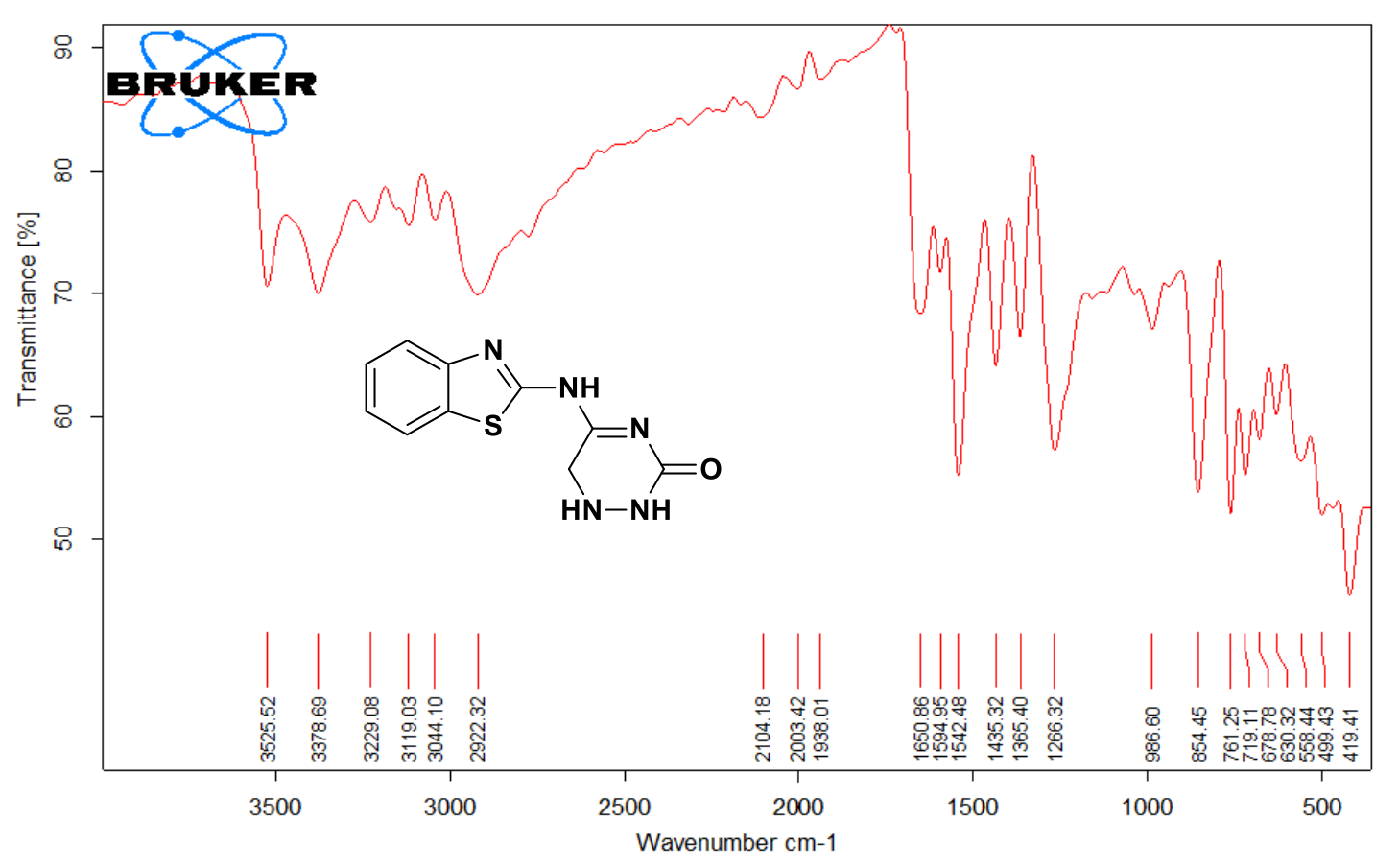

الثكل (2): يوضح طيف الاشعة تحت الحمراء للمركب (2)

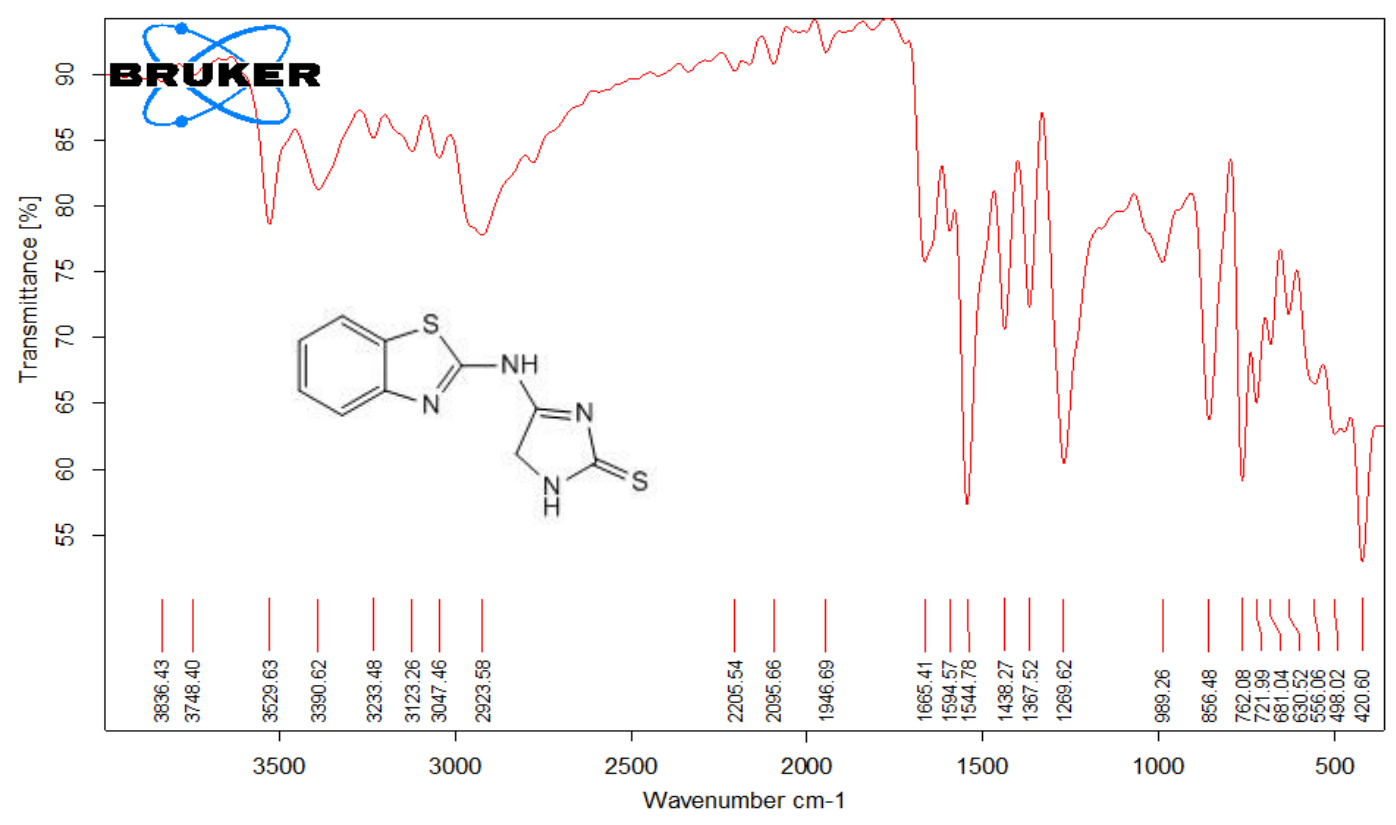

الثكل (3): يوضح طيف الاشعة تحت الحمراء للمركب (5) 


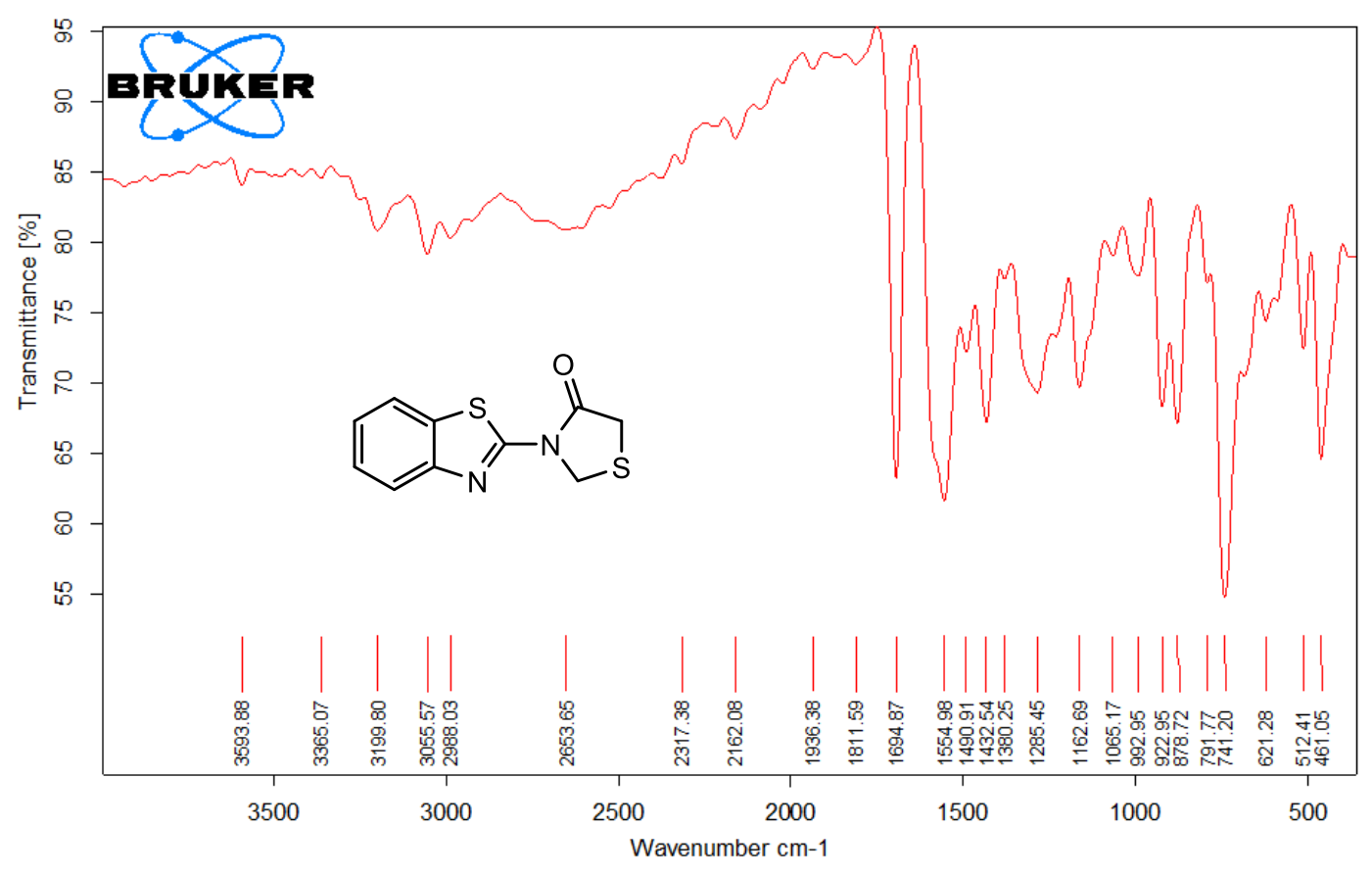

الثكل (4): يوضح طيف الاشعة تحت الحمراء للمركب (6)

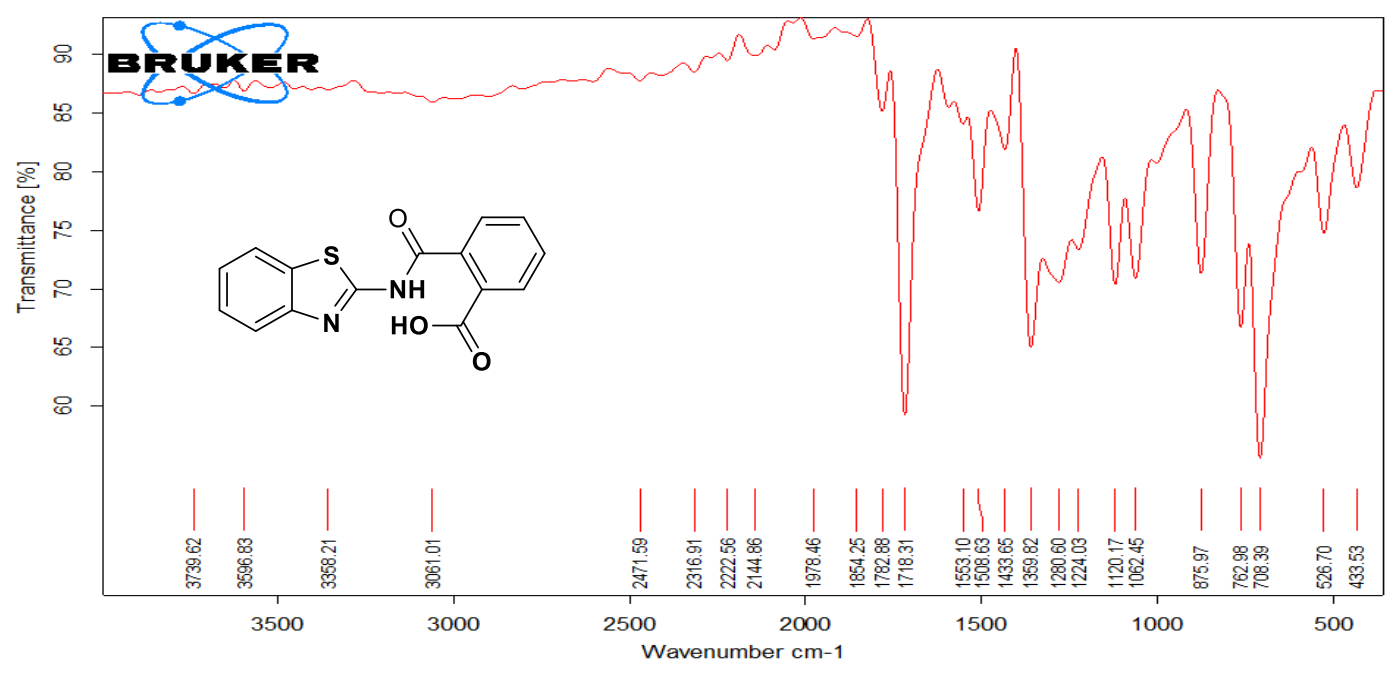

الثكل (5): يوضح طيف الاشعة تحت الحمراء للمركب (8) 

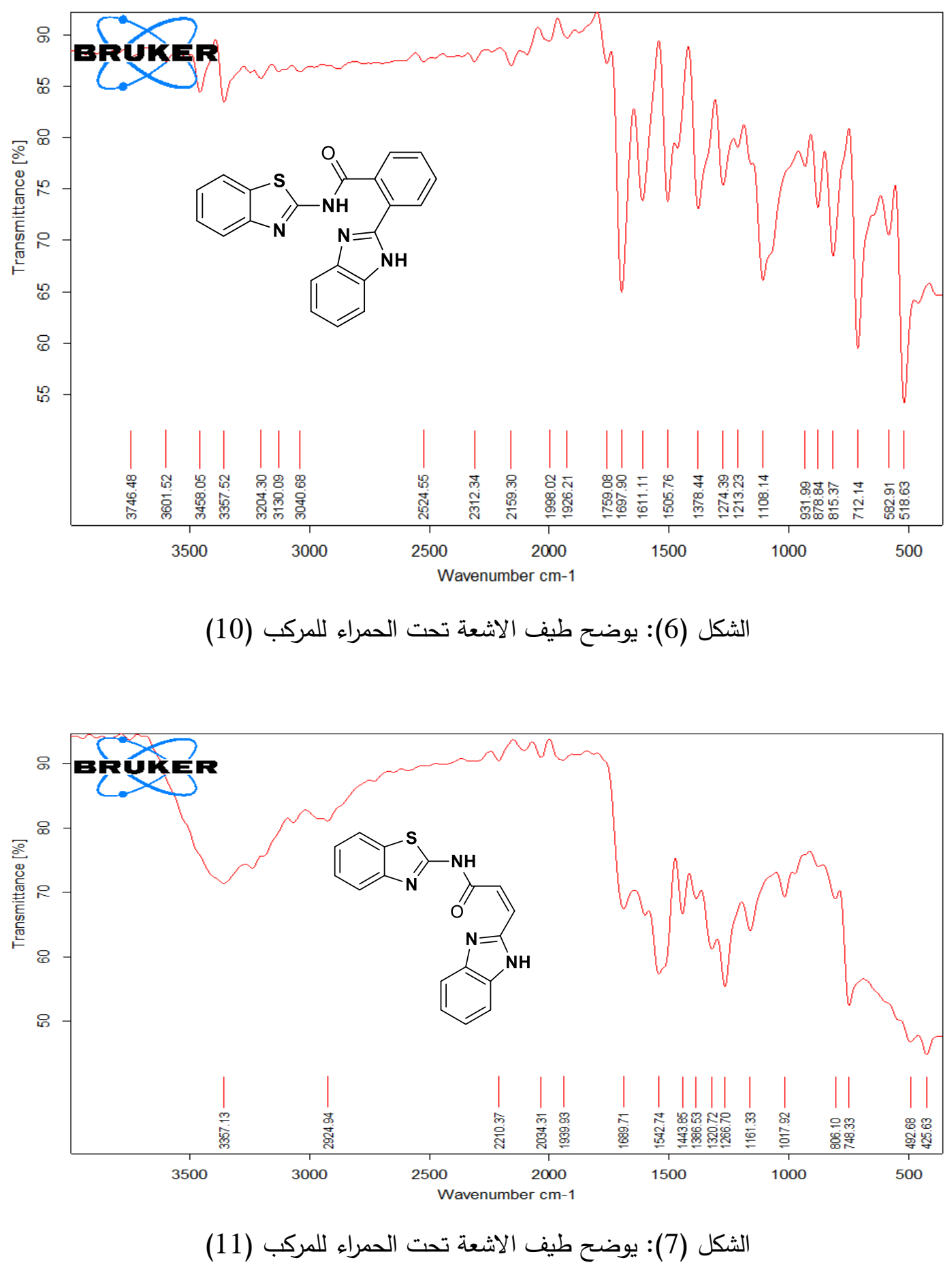


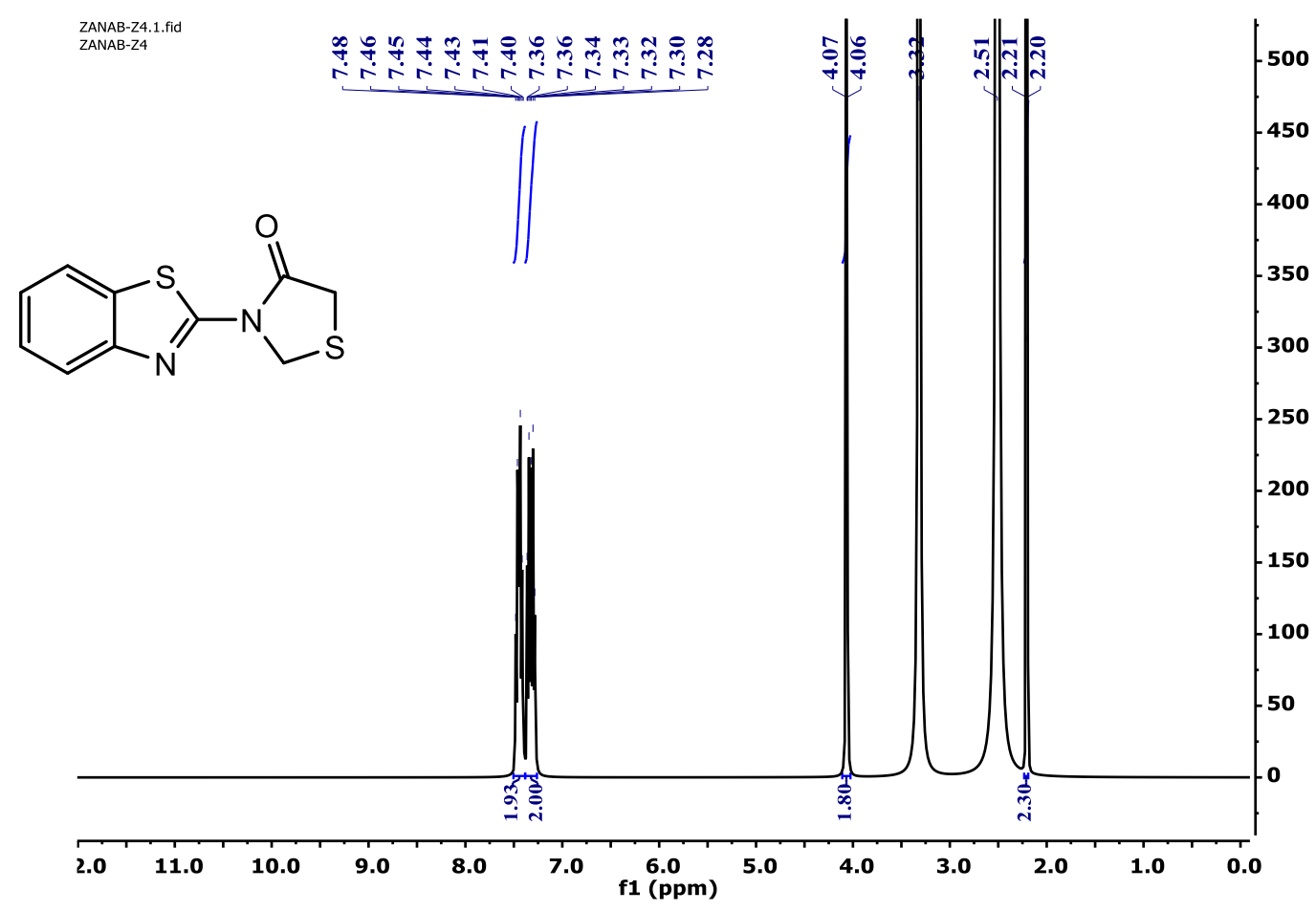

الثكل (8): طيف الرنين النووي المغناطيسي للبروتون (H-NMR )للمركب(6)

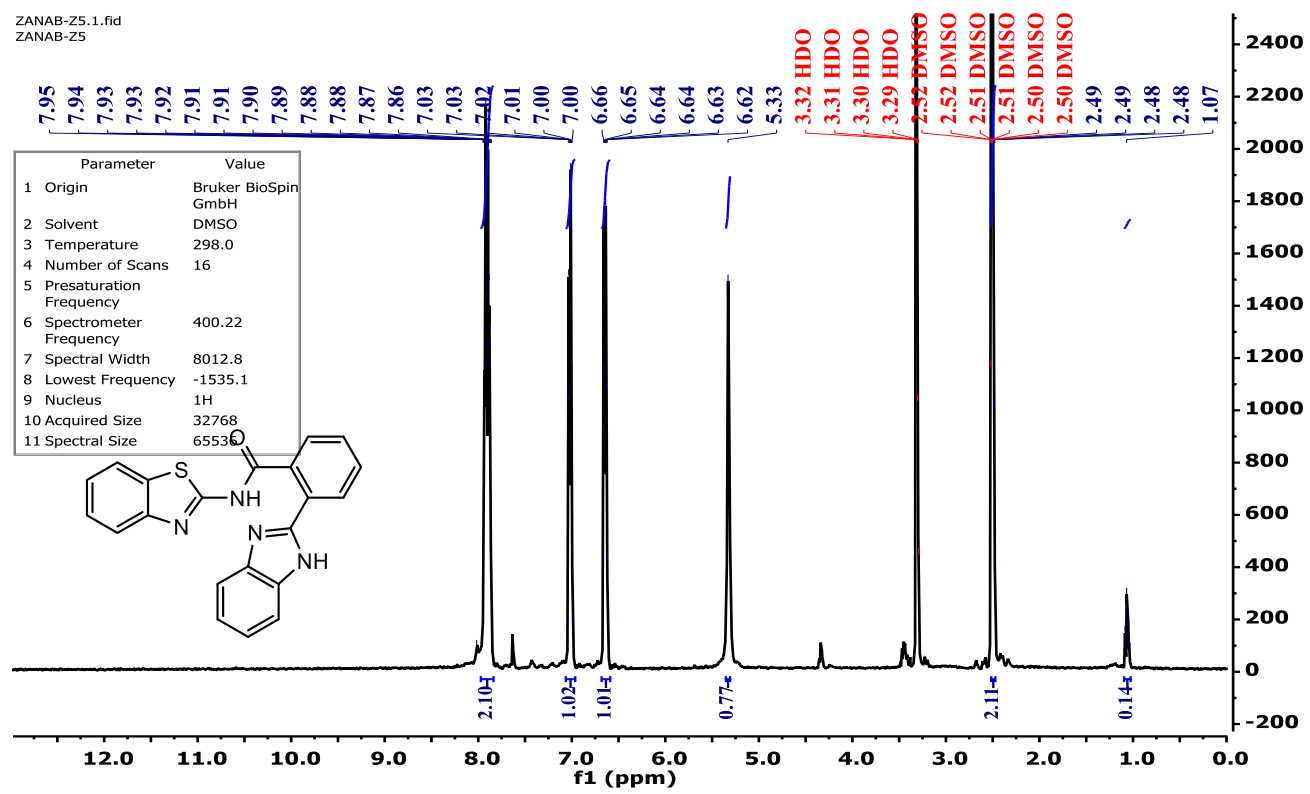

الثكل (9): طيف الرنين النووي المغناطيسي للبروتون (10.0 (10.0 
1. Malik, J.K.; Dr. Manvi, F. V.; Dr. Nanjwade, B. K. and Sajiv Singh, Drug Invention Today, 1(1), 32-34, (2009).

2. Bahaa, S.; Zuhair, M.; Al-Kaissi, E. and Ibrahim, S. A., International of pharmacy and pharmaceutical sciences, 8(4), 189 (2016).

3. Al- Talib, M.; Al-Soud, A. Y.; Abussaud, M. and Khshahneh, S., Arabian Journal of Chemistry, 9(1), 926,(2016).

4. Gnanavel, S.; Kannan, K.; Sowmiya R. and Pachiappan, P., A Journal of the Bangladesh Pharmacological Society, 11(1), 321, (2016).

5. Mahran, A. M.; William S.; Ramzy, F. and Sembel, M. A., Molecules, 12, 622, (2007).

6. Zipeng, G.; Yaping, p.; Jie, Q.; Anbai, C.; Guangcheng W. and Zhiyun, P., Molecules, 22, 1555, 1, (2017).

7. Priya, V.; Frank, K. S. and Girish, B. K., Journal of Indian Chemical Society, 119, 41-46, (2007).

8. Mark, R. T.; Adel, N. and Richard, A. H., Bioorganic Medical Chemical Litters, 12, 3175-3178, (2002).

9. Shelke, RN.; Pansare, DN.; Dake, SA.; Pawar, RP. and Bembalkar, SR., Acta Chim Pharm Indica., 7(4):119, (2017).

10. Scheen, AJ., Diabetes research and clinical practice, 98(2): 175, (2012).

11. Guo, M.; Zheng, C. J.; Song, M. X.; Wu, Y.; Sun, L. P.; Li, Y. J.; Liu, Y. and Piao, H. R., Bioorg Med Chem Lett., 23(15) , 4358 , (2013) .

12. Solomon, VR.; Haq, W. and Srivastava, K., Bioorg Med Chem,; 50:394, (2007) .

13. Patel, N. B. and Patel, S. D., Actapoloniae Pharmaceutical Drug Research, 67, No. 1, 45-53,(2010).

14. Deep, A.; Jain, S. and Sharma, P.C., Acta Poloniae Pharma-Drug Res, 67, 63-67, (2010).

15. Hay, M. P.; Prujin, F.B,; Gamage, S.A.; Liyanage, H. D. and Wilson, W.R., J. Med. Chem. 47, 475, (2004).

16. Baliani, A.; Bueno, G. J.; Stewart, M. L.; Yardley, V.; Brun, R.; Barrett, M. P. and $1 H$ Gilbert, J. Med. Chem. 48, 5570-5579,(2005).

17. Agarwal, A.; Srivastava, K.; Puri, S. K. and Chauhan, P. M. S., Bioorg. Med. Chem. Lett. 15, 531 533, (2005).

18. Pattan, S. R.; Digh, N. S.; Nirmal, S. A. and Musmad D. S., Asian J. Res. Chem., 2(2): 196-201, (2009).

19. Abu-Baker, S. M.; Abu-Zied, K. M.; Youns, M.; Hashim, A. and El-Diwan, H. I., Research Journal of Pharmaceutical, Biological and Chemical Sciences, 4, 1350-1361, (2013).

20. Al-Tintas, H.; Ates, O.; Bir Tekoz, S.; Tuk, G. O.; Uzum, M. and Satano, D., Turk Journal Chemistry, 29, 425-435, (2005).

21. Irina, O. Z.; Sergiy, M. K.; Sergiy, V. V. and Valentin, P. Ch., Molecules, 10, 444-456, (2005).

22. Vinod, K. P.; Mridula, U. and Mrinaljni, U., Acta. Pharm., 55: 47-56, (2005).

23. Abraham, R. J.; Mobli, M. and Smith, R. J., Magn. Reson.Chem., 41: 26-36, (2003).

24. Muhammed, I.; Kumar, N.; Shahida, S. and Zohra, K., IJPSR, 7(5): 1915-1927, (2016).

25. Zhu, J.; Zhang, Z.; Miao, C.; Liu, W. and Sun, W., Tetra Hedron, 25, 73, 3458-3462, (2017). 